\title{
Uma história de regressos: sobre Ó mar de túrbidas vagas, de Henrique Teixeira de Sousa*
}

\author{
Fernando Moreira $^{\dagger}$ \\ Orquídea Ribeiro ${ }^{\ddagger}$ \\ Susana Pimenta ${ }^{\S}$
}

$\begin{array}{lr}\text { Hora di bai, } & \text { Hora de partida, } \\ \text { hora di dor, } & \text { hora de dor, } \\ \text { já'm q'rê } & \text { quero que ela } \\ \text { pa el ca manchê! } & \text { Não aconteça! } \\ \text { Di cada bêz } & \text { De cada vez } \\ \text { qui'm ta lembrâ, } & \text { que nela penso, } \\ \text { ma'm q'rê } & \text { me dá vontade } \\ \text { fica 'm morrê! } & \text { de ficar e morrer! } \\ & \text { Eugénio Tavares }\end{array}$

O romance Ó mar de túrbidas vagas (2005) é um diálogo entre Henrique Teixeira de Sousa e o músico-poeta Eugénio Tavares partilhado desde o título da narrativa, um verso do poema "Canção do Mar", até ao seu encerramento que se desfecha com a entoação por "uma voz dorida de emoção" (SousA, 2005, p. 299), acompanhada pelos sons das cordas de um violão, de um conjunto de versos da mesma "Canção do Mar", ressoando na baía do Mindelo, símbolo e sinal da caboverdianidade:

\footnotetext{
Ó mar eterno, sem fundo,

Sem fim.

Ó mar, de túrbidas vagas,

Ó mar!

De ti e das bocas do mundo

A mim
}

\footnotetext{
Este trabalho é financiado por fundos nacionais através da Fundação para a Ciência e a Tecnologia (FCT), I.P., no âmbito do projeto com a Refa: UID/LIN/oo707/2016.

$\dagger$ Professor doutor da Universidade de Trás-os-Montes e Alto Douro (UTAD), Vila Real, Portugal. E-mail: fmoreira@utad.pt

¥ Professora doutora da Universidade de Trás-os-Montes e Alto Douro (UTAD), Vila Real, Portugal. E-mail: oribeiro@utad.pt

$\S$ Professora doutora da Universidade de Trás-os-Montes e Alto Douro (UTAD), Vila Real, Portugal. E-mail: spimenta@utad.pt
} 
Só me vêm dores e pragas

Ó mar! (SousA, 2005, p. 299)

Nesta sua história de regressos (e para a justificar!), Henrique Teixeira de Sousa aplicou o que Manuel Lopes diz serem as qualidades marcantes da sua condição de homem e escritor: "Quando evoco essa humildade perante a vida, essa tolerância e compreensão humana [...] penso nesse contista evocador do povo da sua ilha vulcânica, Teixeira de Sousa, médico e escritor” (LopEs, 1959, p. 20).

E para melhor exprimir a vida do arquipélago, particularmente esse apego único à terra que está na origem deste retorno, Teixeira de Sousa socorreu-se de um diálogo com as mornas de Eugénio Tavares, poeta em crioulo da sentimentalidade profunda cabo-verdiana, de quem diz Manuel Ferreira que "bastaria o património popular das mornas e canções de Eugénio Tavares para o demonstrar [a vida do arquipélago]" (FERREIRA, 1959, p. 57).

Ó mar de túrbidas vagas é uma espécie de conversa entre dois homens que conheceram a realidade da emigração cabo-verdiana na América: Teixeira de Sousa viveu aí parte da sua infância, levado por um pai que fazia o transporte de mercadorias entre Cabo Verde e os Estados Unidos, e Eugénio Tavares para lá partiu como exilado e aí ficou, durante os primeiros anos do século XX, desenvolvendo intensa atividade jornalística cujo tema dominante era a realidade social e económica de Cabo Verde. Luiz Silva afirma mesmo que Eugénio Tavares se exilou nos Estados Unidos, levado por uma necessidade de escapar à perseguição política e muito provável prisão, o que é certo, mas aproveitou tal situação para "trabalhar e estudar os vários aspectos da emigração. Viveu e partilhou com suor e sangue o dia a dia do emigrante cabo-verdiano nas fábricas, nas associações e nas organizações sindicais" (SILVA, 2006, p. 26).

Inspirado, portanto, na morna "Canção do Mar" de Eugénio Tavares, Túrbidas Vagas é também um registo autobiográfico já que Hilário Cardoso, personagem principal, cumpre decalcadamente a figura paterna de Henrique Teixeira de Sousa, assim apresentado por ele mesmo a Michel Laban:

O meu pai era marítimo, capitão de veleiro. Ele era da ilha Brava e casouse no Fogo com a minha mãe. E no Fogo se fixou até ao fim da vida. Foi homem de mar até os 50 anos de idade, altura em que vendeu o último veleiro e se decidiu a montar comércio e a cultivar as propriedades rústicas adquiridas com o dinheiro ganho de riba da água do mar. Adaptouse tão bem às novas actividades como se continuasse a bordo do Corona, seu último palhabote (SousA apud LABAN, 1992, p. 173).

Concordando com Maria Turano, Teixeira de Sousa mais não faz do que expressar e transformar a sua recordação memorial pessoal numa voz da memória coletiva de Cabo Verde: "Em Teixeira de Sousa, a modalidade de expressão da recor- 
dação é a narração escrita: a lembrança é pessoal, mas ela torna-se também portavoz duma memória colectiva" (TuRANo, 2000, p. 225).

Também as circunstâncias algo atribuladas da viagem de regresso (símbolo de outros tantos retornos sempre desejados e nem sempre possíveis ou concretizados), que constitui a ação principal da narrativa, foram inspiradas na realidade vivida pelo próprio autor aquando do seu retorno a Cabo Verde, após estadia prolongada nos Estados Unidos:

Lembro-me da longa viagem de 44 dias de Providence à ilha de S. Vicente, onde meu pai nos esperava cheio de aflições. A demora da travessia foi devida a uma avaria do cronómetro [...]. Assim passamos para a navegação estimada até nos acontecer um facto providencial. Foi o aparecimento de um cargueiro a vapor que nos ofereceu as coordenadas, água e alimentos variados. [...] Cada viagem para a América, ou da América para Cabo Verde, naqueles veleiros, era uma aventura. Muitos barcos desapareceram engolidos pelo oceano, muito luto cobriu as ilhas durante perto de um século, nesse vaivém entre Cabo Verde e América. Esta história trágicomarítima está ainda por escrever (SousA apud LABAN, 1992, p. 179). ${ }^{1}$

Sem ser a escrita desta história trágico-marítima, embora reclame aí o seu espaço e contributo para memória futura, em Ó mar de túrbidas vagas expressam-se os riscos constantes do movimento migratório entre Cabo Verde e os Estados Unidos da América: perigos de navegação, circunstâncias difíceis, esperanças afundadas, mortes e tragédia de um povo.

O registo autobiográfico também se estende ao episódio da paragem do cronómetro (SousA, 2005, p. 30-31) que levou a que a embarcação do capitão Hilário andasse à deriva em "navegação estimada" (SousA apud LABAN, 1992, p. 179) até que apareceu um cargueiro que os rebocou de volta à rota e regulou o cronómetro. Para Teixeira de Sousa, episódios como este tornavam as viagens de e para a América numa aventura, com "muitos barcos [a] desaparecer[e]m engolidos pelo oceano (SousA apud LABAN, 1992, p. 179).

Partir para a América foi a tábua de salvação dos cabo-verdianos em dado momento da sua história, ao mesmo tempo que um ato de libertação; os Estados Unidos tornaram-se, por esse tempo, no "único espaço no mundo onde Cabo Verde poderia sobreviver", segundo confidenciou Teixeira de Sousa a Michel Laban (SousA apud LABAN 1992, p. 181). Gerou-se, assim, um movimento, um trânsito, quantas vezes ilegal, de gente e mercadorias, feito em condições maioritariamente precárias de uma terra madrasta para o El Dorado e deste para a terra da saudade. Nesse movimento seguiram também as tradições culturais, os usos e costumes de um povo orgulhoso da sua pertença às ilhas. De facto, a realidade da emigração

\footnotetext{
- Esta circunstância, aqui narrada em entrevista a Michel Laban, foi, em primeira mão, relatada no seu conto "Contra mar e vento".
} 
cabo-verdiana para a América é também a história de um povo que transportou a sua cultura e, assumindo-a talvez pela primeira vez de forma consciente, fez dela um fator de união, sobrevivência e afirmação identitária na terra de acolhimento. Teixeira de Sousa explica a Michel Laban, de forma clara e lapidar, esta realidade:

A comunidade cabo-verdiana dos Estados Unidos conserva o seu património cultural, incluindo as gerações ali nascidas. Não consegue penetrar na sociedade americana, nem na branca nem na negra. Em cada cidade, em cada estado, os cabo-verdianos vivem num arquipélago, separado não pelo mar, mas pelas milhas terrestres que medeiam entre os diversos núcleos e separados da sociedade americana pelos conhecidos preconceitos racistas. Mas vivem felizes, nunca esquecendo a mátria, até mesmo aqueles que são nados e criados sob a bandeira das 50 estrelas (SousA apud LABAN, 1992, p. 183). ${ }^{2}$

Nhô Boaventura e nhô Almancinho, duas das personagens que regressam em definitivo dos Estados Unidos para Cabo Verde, são bem dois exemplos ilustrativos desta insularidade vivida em terra alheia, desse apartamento social e cultural tantas vezes justificado pelo ambiente rácico que a América de então, no final dos anos 2o, enfrentava; a ação decorre no ano que antecede a Grande Depressão de 1929; e com o episódio do relato de uma situação vivida por Hilário Cardoso e o seu irmão Eugénio, Teixeira de Sousa denuncia a contribuição que o racismo, então latente em terras americanas, dava para esta existência de verdadeiros guetos culturais:

Não pareciam irmãos, ele branco, de cabelos lisos, o irmão bastante trigueiro, de cabelo frisado. Foram uma vez a um barber's shop para cortar o cabelo e à entrada um dos barbeiros pediu desculpa ao Eugénio, por não o poder atender, não pelos profissionais do estabelecimento, mas por causa dos clientes. E acrescentou: o seu amigo pode ficar. [...] Havia muito racismo naquelas latitudes (SousA, 2005, p. 20-21).

O racismo e a discriminação racial acompanhavam a Grande Depressão ${ }^{3}$, que teve um impacto considerável nos Estados Unidos, traduzindo-se em falta de confiança na economia e consequente desemprego e pobreza (History.Com, 2009a),

2 Já o poeta José Lopes tinha feito uma afirmação semelhante no artigo "Arquipélago de Cabo Verde", publicado no Boletim da Agência-Geral das Colónias: "São famosos os nossos marinheiros, dignos filhos de Portugal. A colónia caboverdeana dos Estados Unidos da América do Norte é um exemplo o mais grandioso da actividade dos nossos compatrícios e do seu amor à terra natal e à gloriosa Mãe Pátria. Vão para aquele grande país, trabalham sem se pouparem e poupam sempre trabalhando, mas nem a ausência vice-morte nem as separações prolongadas (às vezes para sempre!...) nem os encantos da civilização yankee conseguem arrancar-lhes da alma a imagem querida e saudosa das suas ilhas natais" (Lopes, 1929, p. 212). Ver também Almeida (1925, p. 90).

3 A Grande Depressão teve início em 1929 com a queda da Bolsa de Valores de Nova Iorque e terminou em 1939. Em 1933 havia cerca de 15 milhões de desempregados, levando o governo federal a apoiar programas de emprego federais para reduzir o desemprego (History.com, 2009a). 
retorno de imigrantes aos países de origem e a continuação da grande migração ${ }^{4}$ dos afro-americanos dos estados do Sul para os centros urbanos do Norte, que procuravam trabalhadores para as indústrias no pós Primeira Guerra Mundial, fugindo às poucas oportunidades económicas e às duras leis da segregação nos locais de origem (History.Com, 2009b), mas tendo que enfrentar condições de trabalho inadequadas, como é referido no romance de Teixeira de Sousa: "[Nhô Boaventura] costumava contar que uma ocasião não morreu por um triz, graças à sua agilidade. Uma montanha de carvão desmoronou-se e matou seis companheiros" (SousA, 2005, p. 68).

Veja-se então quem são os protagonistas desta história de regressos e que memórias identitárias trazem consigo.

Hilário Cardoso, um capitão de veleiro na casa dos 50 anos, fazia transportes de mercadorias e alguns passageiros entre as ilhas de Cabo Verde e a América do Norte, sobretudo Providence, Rhode Island e New Bedford, Massachusetts, assim como para a costa de África. Fazia o mesmo que tantos outros antes dele fizeram:

Na realidade, existiam itinerários comerciais estabelecidos durante as estações: numa certa altura do ano, os veleiros levavam para a América passageiros e produtos da terra, e regressavam, com outras mercadorias. Entre uma viagem e outra para a América, viajavam para a costa de África afim de transportar passageiros e mercadorias (TuRANO, 2000, p. 231).

Com a crise americana a afetar o seu modo de vida, Hilário decide regressar em definitivo à terra de onde partiu e fixar-se no seu cantinho, dedicando-se ao comércio e à agricultura:

Entretanto, surgira a crise americana, que prometia durar. Os patrícios que trabalhavam no carvão, nos têxteis, na pesca da baleia, na apanha do morango, nos restaurantes, viviam em sobressalto por causa dos despedimentos e lay-offs que não paravam. De sorte que urgia estabelecer uma base sólida de sobrevivência na terra e esquecer Providence e New Bedford para sempre (SousA, 2005, p. 7).

Sem ser emigrante, Hilário vivia da emigração; era um homem bem formado, tendo frequentado, por cinco anos, o seminário/liceu do Mindelo; bom aluno, contrariou a intenção paternal de seguir a vida eclesiástica (era muito bom em latim) ao assumir uma profissão que melhor o identificava como cabo-verdiano:

As velas enfunadas, os relatos das viagens tormentosas, a dignidade dos melhores capitães fascinavam-no ao ponto de também querer integrar-se

4 A Grande Migração teve início por volta de 1910 e estendeu-se até 1970, sensivelmente (History.com, 2009b). 
nessa equipa de homens valentes que demandavam os portos longínquos para ganhar o sustento da família. Não só da família como duma população inteira. O que seria de Cabo Verde sem as escunas, os palhabotes, até mesmo os faluchos?" (SousA, 2005, p. 19).

Frequentou a escola de pilotagem em S. Vicente e embebeu-se nesse ambiente de mar e terra que bem identifica Cabo Verde, particularmente simbolizado pelo fervilhar das ruas da baía do Porto Grande:

Gostava imenso de passar pela Rua dos Botes, afinal de contas era a rua onde funcionava a sua escola, para olhar para a baía repleta de mastros e chaminés, para ouvir o ruído das vagonetas de carvão, para haurir o cheiro da maresia nos dias de ventania. A Travessa da Praia, a Rua de Santo António, mais conhecida por Rua da Canecadinha, o Largo da Salina, tudo lugares de muita gente, inúmeras tascas, marinheiros estrangeiros, cães vadios, prostitutas à caça de clientes, todo esse rumor de vida extasiava-o, no pico da sua juventude (SousA, 2005, 19-20).

O capitão cumpria, com o seu regresso definitivo à terra e ao torrão natal, com o seu retorno aos espaços fervilhantes de vida e cheiros únicos e à calmaria indolente do viver das ilhas, o destino do cabo-verdiano individualizado que se tornou peça essencial, porta-voz, pedra viva e modelo da identidade coletiva de Cabo Verde.

Agora era o ambiente mar e terra que o reclamava, ansiando por tranquilidade na companhia da família "no seu lar em S. Filipe ou a sua casinha de Lagariça, atrás do balcão ou do pessoal da monda, ouvindo o balido das cabras, o ruflar das asas das codornizes, o zurrar dalgum burro, lá longe, ao cair da tarde. Aí não haveria o tédio das viagens ou as surpresas do mar" (SousA, 2005, p. 20), longe dos perigos da navegação, cumprindo, aliás, uma máxima do seu avô materno que afirmava ser a vida do cabo-verdiano "como a lançadeira de máquina de costura, terra mar, mar terra" (SousA, 2005, p. 26) num vaivém inconstante de um "povo sem o sossego da estabilidade" (SousA, 2005, p. 26).

Hilário era um homem educado, com bons princípios; no pensamento da insinuante Libânia, outra dos regressados, Hilário "era mesmo um homem em todos os sentidos, alto, corpulento sem ser gordo, educado e amigo da família" (SousA, 2005, p. 43).

Hilário regressava também para Berta, o seu amor sereno e reconfortante, como a terra que o chama, que em jovem o curara de uma paixão assolapada "como a cornada dum boi" (SousA, 2005, p. 49) que Maria das Dores, filha do senhor Protásio, seu primeiro mestre, nele despertara: "Aquilo que sentia pela Berta era diferente, quiçá mais gostoso do que o atordoamento provocado pela filha do senhor Protásio" (SousA, 2005, p. 49). 
Com o regresso, o capitão realizava o seu amor embalado pelas palavras sábias do poeta Eugénio Tavares: "amor sabi ê na dibagarinho" - "Amor saboroso é aquele que se curte na tranquilidade" (SousA, 2005, p. 49). Mas regressava também para um outro amor porque "sentia saudades do cheiro da terra molhada, do roçar rumoroso das folhas do milheiral, do ronronar do moinho, do ritmo do pilão, do cantar do galo e sobretudo da companhia da mulher no descanso da noite" (SousA, 2005, p. 54), enfim, pela nostalgia da terra firme: "Havia chegado a hora de pôr definitivamente os pés em terra, ainda em condições físicas e mentais de gozar a vida tranquila" (SousA, 2005, p. 94).

Mas não há dádiva sem paga e o regresso de Hilário Cardoso é cobrado pela partida do seu filho homem que o irá substituir no mar, espaço de destino comum dos cabo-verdianos - "O nosso destino em Cabo Verde é o mar, assim nos dizia nhô Talefe" (SousA, 1998, p. 118) - e elemento entranhado no quotidiano e identidade cultural de Cabo Verde: "Ti Alfredo, o mar faz parte do nosso dia a dia, da nossa cultura" (SousA, 1998, p. 123).

Se o capitão Hilário Cardoso viaja definitivamente para o remanso do lar (mulher-mãe e terra-mãe), Libânia Burgo, outra dos regressados, deixou a América porque "dava-se mal com o marido, este andava metido no fabrico e tráfico clandestino de aguardente, o tal moonshine, embebedava-se e chegava a agredi-la severamente" (SousA, 2005, p. 10). Perdera o emprego, o marido foi preso e resolveu regressar, mas a pensar partir de novo para os States, caso a necessidade ocorresse.

Libânia é uma aculturada assumida, uma torna-viagem que adquiriu a cidadania americana e era dona de um amplo e bom apartamento em New Bedford; era sua intenção, neste regresso, montar um negócio, mais concretamente uma padaria em Nova Sintra, sua aldeia natal na Brava, porque "A América para ela, foi uma decepção. Era só trabalhar, trabalhar e aguentar as exigências dos bosses e as chatices de um mau casamento" (SousA, 2005, p. 44).

Emigrara com 23 anos, já mulher feita, e estivera 22 anos na América; agora "achava-se de volta à sua ilha, até porque os States já não estavam como eram. Enfim, era uma experiência. Se não desse resultado, embarcaria de novo para lá" (SousA, 2005, p. 73-74).

Bonita, educada e simpática, ela será a voz maioritária e rememoriada de Eugénio Tavares neste diálogo com Henrique Teixeira de Sousa, pois saíam da sua boca as cantigas do poeta celebrado das mornas, numa expressão definitiva de um amor à terra fortemente enraizado. Nesse papel, nessas cantigas em crioulo que lhe saem dos lábios empurradas por uma memória que julgava não mais existir, Libânia expressa a língua da identidade sempre reivindicada pelos cabo-verdianos emigrados.

Do alto da sua aculturação, a sofrida e desiludida Libânia expressa os efeitos da mesma e torna-se porta-voz de um novo cabo-verdiano que expõe os anacronismos de uma sociedade e contesta o que considera ser o espetáculo hipócrita de 
um funeral cabo-verdiano por oposição ao "nojo civilizado" com que se choram os mortos nos Estados Unidos:

Da igreja saía um funeral, acompanhado por muito povo vestido de preto. Atrás do caixão seguia um grupo de mulheres numa cantilena dorida que há muitos anos ela não ouvia. Nos States não se chora assim um morto. Nos funeral-houses as pessoas comportam-se com discrição, a viúva ou o viúvo apresenta-se bem arranjado, atencioso para com os parentes e amigos, disponível para as sandwiches e juices que vão aparecendo. [...] Quando é que acabam com isto? Na América não é assim” (SousA, 2005, p. 70-71).

A ociosidade que verificou quando passeava pelas ruas do Mindelo também lhe mereceu um comentário "americano" bem áspero: "Desculpem a interrupção, estes homens não têm que fazer?” (SousA, 2005, p. 75). Situação idêntica foi assinalada por (Coronel) João de Almeida em 1925 ao afirmar que "Em Cabo Verde, [o cabo-verdiano] é imprevidente, sem estímulo pelo trabalho, descurando tudo" (AlmEIDA, 1925, p. 90) e igualmente por José Lopes que confirma a ideia da ociosidade preguiçosa: "Os homens caboverdianos são mais activos nos países de emigração do que nas suas ilhas [...] encontram-se muitos indivíduos apáticos, indolentes [...] que em toda a sua vida nada mais fazem do que preguiçar" (LOPES, 1929, p. 212).

Libânia mergulhava aos poucos na realidade cabo-verdiana que a distância temporal de vinte e dois anos fizera esquecer - o choro das carpideiras, a guisa, e a abundância de moscas à volta dos alimentos eram apenas dois exemplos. Uma simples ida à casa de banho acabou-lhe com as ilusões, mas tornou-a firme na convicção de alterar certas coisas dessa mesma realidade que persistia:

A retrete era no quintal, num casinhoto também muito asseado, com dois penicos altos e uma selha cheia de água. Folhas do Notícias de Cabo Verde estavam ali à disposição dos necessitados. Foi o reencontro mais penoso com as realidades da terra. Na sua aldeia de Lavadura teria de se readaptar a muitas coisas mais, após vinte e dois anos doutras comodidades. Iria entretanto tentar alterar certos hábitos, como, por exemplo, o uso da casinha no meio da horta para alívio de certo tipo de dor de barriga. Na América, onde não há rede de esgoto, cava-se uma fossa. Mas lá se ajeitou e até se lavou, após a leitura do jornal (SousA, 2005, p. 77).

Mas Cabo Verde exercia a sua atração, o seu inigualável donaire; a beleza do porto do Mindelo ao sol-pôr, num final de dia ensolarado, mostrou a Libânia algo bem mais agradável, pois colocou-a perante uma "aguarela dum pôr-do-sol nunca visto pela visitante" (SousA, 2005, p. 83) e lhe mereceu um comentário 'americano': “- Nem na Florida vi coisa igual” (SousA, 2005, p. 83). A simpatia natural das pessoas cativava-a, do casal dono da casa de pasto (que estivera emigrado na 
Argentina) ao capitão Alfredo e ao fotógrafo Jonjón, figurantes de um quadro vivo, cativante e único, bem ao invés dos deslocados e estranhos ingleses aí residentes que viviam apartados de tudo e de todos, um tanto à maneira dos americanos que segregavam os negros: "alguns patrícios, de pele mais chamuscada, queixavam-se de racismo dos americanos” (SousA, 2005, p. 86).

O Mindelo e as suas "facilidades normais de intercomunicação entre as classes (muito mais do que entre as ilhas e entre os povoados), a mobilidade vertical e horizontal que está na base do comportamento social deste povo" (LOPES, 1959, p. 12), S. Vicente onde "as classes sociais [...] já se apoiavam mais no poder económico do que na pigmentação da pele" (LoPEs, 1959, p. 12), trouxe também Libânia a uma nova realidade social que lhe agradava e muito diferente da da sua ilha Brava e do vivenciado nos Estados Unidos; por isso, foi com satisfação que se sentiu tratada como gente: "Até que enfim a tratavam como gente e não como uma cadela em período de cio" (SousA, 2005, p. 97); do estranhamento ao entranhamento foi um passo muito curto: a identidade, a memória falaram mais alto.

Almancinho de Pina era uma cabo-verdiano emigrado sozinho nos Estados Unidos; tomado por uma tuberculose em estado final, embarcou no veleiro de Hilário Cardoso para vir morrer à terra neste seu regresso; embarcara mal trajado, barba por fazer, quase um pedinte, de tal forma que o capitão lhe fez $50 \%$ de desconto na passagem; contudo, escondia nos bolsos de uma calças velhas uma pequena fortuna em dólares. Almancinho "ostentava mau aspeto, muto magro e tossicando constantemente [...] o homem se achava muito doente e desenganado pelos doutores. Tinha os dois pulmões devastados por doença cancerosa" (SousA, 2005, p. 8). Antigo saxofonista com aspeto dos "famintos das secas" (SousA, 2005, p. 23), morreu em plena viagem, em 12 de agosto de 1928, calmamente como o mar chão em que navegavam, e aí foi sepultado; cumpria assim o destino de tantos caboverdianos emigrantes, atores de uma história trágico-marítima ainda não contada, heróis trágicos que, de um modo ou de outro, forma vítimas de uma odisseia que os sepultou no mar como pagamento da sua heroicidade.

O último elemento dos regressados era nhô Boaventura do Curral d'Ochoa, ilha do Fogo. Era um chico-esperto; pastor quando criança, embarcou num navio baleeiro que abandonou quando chegou aos Estados Unidos. Andou por lá trinta e sete anos dos seus cerca de sessenta. Regressava para se casar e ter filhos, algo que não realizara até então: "Vinha com intenções de arranjar uma companheira parideira a fim de que pudesse deixar descendentes" (SousA, 2005, p. 58). A sua condição de emigrante levou-o a trabalhar nas docas de New Bedford, no carvão, de onde regressava "mais negro do que era, pois nem casa de banho havia para se lavarem a preceito" (SousA, 2005, p. 68). Tirando umas palavras em inglês e uma reclamação de supostos direitos como se faz na América, Boaventura regressa como foi ou pior: antes era analfabeto, agora continua a sê-lo, para além de medroso, quezilento, voyeur e mentiroso (recebeu a alcunha no barco de Boa-mentira). Depois de ter apanhado uma doença venérea com uma prostituta no Mindelo e de ver os seus 
planos de constituir família ir por água abaixo por isso mesmo, Boaventura persiste na sua obstinação em obter uma indemnização do capitão do navio, culpandoo da doença que não queria revelar e que mereceu um elucidativo comentário do subdelegado de justiça que afirmou que alguns "iam burros e regressavam bestas da América” (SousA, 2005, p. 171). Boaventura cumpria, também ele, o destino de muitos emigrantes: estranhos na terra de acolhimento, estranhos na própria terra.

O que leva personagens tão diferentes como Hilário Cardoso (emigrado no mar Atlântico a bordo dos seus barcos), Libânia, Almancinho e Boaventura a regressar? Que chamamento, que apelo tão forte os conduz de regresso às ilhas? São, como dizem as palavras de um batuque de Santiago, os que vêm em busca do coração que ficou nas ilhas quando partiram: "O corpo que é escravo vai / coração que é livre fica" (Silva, 2006, p. 30). É o apelo da terra vertido, qual canto da sereia, pelas palavras melodiosas das mornas de Eugénio Tavares que tão bem exprimem a vivência cabo-verdiana, a saudade, a morabeza, a emoção, a sentimentalidade da mestiçagem cultural numa língua única que se institui, para o caboverdiano e em particular para o cabo-verdiano emigrado, como um "autêntico reduto colectivo de um povo que encontra assim um modo muito próprio de se afirmar como singularidade" (FerReIRA, 1959, p. 58); em especial para os emigrantes, como refere Luiz Silva, "o crioulo será [...] a língua da identidade reivindicada [...] e exercerá um papel dinâmico nas relações entre Cabo Verde e a sua emigração" (SILVA, 2006, p. 26); ora, é esse o papel que as mornas de Eugénio Tavares desempenham em Ó Mar de Túrbidas Vagas. Em todo o caso, e definitivamente, como vem escrito no romance, a "nossa terra é sempre nossa terra" (SousA, 2005, p. 74), se bem que, conforme observado pertinentemente por Graça Pina:

A pertença, além de se religar ao espaço físico (à terra-mãe, por assim dizer), no caso cabo-verdiano, prende-se intimamente com a língua. É a língua crioula que conserva a especificidade da identidade cabo-verdiana. É nela e através dela que o cabo-verdiano [...] estabelece a sua ligação com a terra, com as ilhas (PINA, 2010, p. 186).

Manuel Lopes caracteriza a literatura cabo-verdiana como "a literatura de expressão de motivos cabo-verdianos, [...] [a] literatura que traduz a sensibilidade e a idiossincrasia do povo daquele Arquipélago", logo textos com "características inconfundíveis" (LOPES, 1959, p. 15) como Ó mar de túrbidas vagas de Henrique Teixeira de Sousa, uma narrativa de memória pessoal que se consubstancia em memória coletiva.

\section{Referências}

AlmeidA, João. O Pôrto Grande de São Vicente de Cabo Verde. Boletim da AgênciaGeral das Colónias, Lisboa, v. 1, n. 3, p. 78-115, 1925. 
Ferreira, Manuel. Comentários em torno do bilinguismo cabo-verdiano. Revista da funta de Investigação do Ultramar, Lisboa, n. 22, Colóquios Cabo-Verdianos, p. 51-81, 1959 .

History.com. Great Depression. New York: A+E Networks, 2009a. Disponível em: http://www.history.com/topics/great-depression. Acesso em: 18 jul. 2017.

History.com. Great Migration. New York: A+E Networks, 20ogb. Disponível em http://www.history.com/topics/black-history/great-migration. Acesso em: 18 jul. 2017.

LabAN, Michel. Encontro com Henrique Teixeira de Sousa (entrevista). Cabo Verde - Encontro com Escritores. Porto: Fundação Eng. António Almeida, v. 1, p. 150-22o, 1992.

Lopes, José. Arquipélago de Cabo Verde. Boletim da Agência-Geral das Colónias, Lisboa, v. 5, n. 45, p. 201-214, 1929.

LOPES, Manuel. Reflexões sobre a literatura cabo-verdiana. Revista da funta de Investigação do Ultramar, Lisboa, n. 22, Colóquios Cabo-Verdianos, p. 1-22, 1959.

PinA, Maria da Graça Gomes de. Viagens e paragens de (e na) literatura caboverdiana. Revista Confluenze, Bolonha, v. 2, n. 1, p. 185-196, 2010.

Silva, Luiz. Os exílios na literatura caboverdiana. Latitudes - Cahiers Lusophones, Nyons, n. 27, p. 23-30, 2006.

SousA, Henrique Teixeira de. Capitão de mar e terra. Lisboa: Europa-América, 1998.

SousA, Henrique Teixeira de. Ó mar de túrbidas vagas. Lisboa: Plátano, 2005.

Turano, Maria R. Memória e identidade nos contos de Teixeira de Sousa (para uma antropologia da literatura). Revista Via Atlântica, São Paulo, n. 4, p. 224-236, 2000.

Recebido em 30 de janeiro de 2018.

Aprovado em 15 de julho de 2018. 


\section{Resumo/Abstract/Resumen}

Uma história de regressos: sobre $O$ mar de túrbidas vagas, de Henrique Teixeira de Sousa

\section{Fernando Moreira, Orquídea Ribeiro e Susana Pimenta}

Henrique Teixeira de Sousa desenvolve na obra Ó mar de túrbidas vagas uma história de regressos cujo pano de fundo é a emigração cabo-verdiana para os Estados Unidos da América. De forma subtil, o autor reflete sobre aspetos da identidade cabo-verdiana num cruzamento bem-sucedido entre a sua escrita e os versos do poeta Eugénio Tavares, que cita de modo recorrente, e cujas palavras enformam esta história de regressos. Refletir sobre a obra de Henrique Teixeira de Sousa, a sua visão sobre a cabo-verdianidade e, em particular, sobre a emigração e os efeitos socioculturais consequentes tomando como ponto de partida o romance Ó mar de túrbidas vagas é o objeto de estudo que se propõe.

Palavras-chave: Henrique Teixeira de Sousa, identidade, caboverdianidade, regresso, emigração.

\section{A history of returns: on Ó mar de túrbidas vagas, by Henrique Teixeira de Sousa}

\section{Fernando Moreira, Orquídea Ribeiro and Susana Pimenta}

Henrique Teixeira de Sousa develops, in his work Ó mar de túrbidas vagas, the story of homecomings whose background is Cape Verdean emigration to the United States of America. The author subtly reflects on aspects of Cape Verdean identity in a successful interlacement of his writing and the verses of the poet Eugénio Tavares, whom he recurrently cites, and whose words shape this story of homecomings. Taking as a starting point the novel Ó mar de túrbidas vagas, this study reflects on the work of Henrique Teixeira de Sousa, his vision of Cape Verdean identity and, in particular, of the emigration and the consequent sociocultural effects brought about by it.

Keywords: Henrique Teixeira de Sousa, identity, Cape Verdean identity, homecoming, emigration.

Una historia de regresos: sobre Ó mar de túrbidas vagas, de Henrique Teixeira de Sousa

\section{Fernando Moreira, Orquídea Ribeiro y Susana Pimenta}

Henrique Teixeira de Sousa aborda en la obra Ó mar de túrbidas vagas una historia de regresos cuyo telón de fondo es la emigración caboverdiana a los Estados 
Unidos de América. De forma sutil, el autor reflexiona sobre aspectos de la identidad caboverdiana en una confluencia exitosa entre su escritura y los versos del poeta Eugénio Tavares, al cual cita de modo recurrente y cuyas palabras informan esta historia de regresos. Reflexionar sobre la obra de Henrique Teixeira de Sousa, acerca de su visión de la caboverdianidad y en particular sobre la emigración y los efectos socioculturales consecuentes tomando como punto de partida la novela $O$ mar de túrbidas vagas, es el objeto de estudio propuesto.

Palabras clave: Henrique Teixeira de Sousa, identidad, caboverdianidad, regreso, emigración. 